\title{
VITIS VINIFERA L. AND SAMBUCUS NIGRA L. EXTRACTS ATTENUATE OXIDATIVE STRESS AND INFLAMMATION IN FEMORAL ISCHEMIA
}

\author{
CRISTINA BIDIAN ${ }^{1}$, DANIELA-RODICA MITREA ${ }^{1 *}$, CORINA TATOMIR $^{2}$, MARIA PERDE- \\ SCHREPLER $^{2}$, CAMELIA LAZĂR ${ }^{3}$, IOANA CHET TNAN ${ }^{1}$, POMPEI BOLFA ${ }^{4,5}$, LUMINIȚA $^{2}$ \\ DAVID $^{6}$, SIMONA CLICHICI ${ }^{1}$, GABRIELA ADRIANA FILIP ${ }^{1}$, MARIANA MUREŞAN ${ }^{7}$, \\ OTILIA MICLE ${ }^{7}$
}

\author{
${ }^{1}$ Department of Physiology, "Iuliu Haţieganu” University of Medicine and Pharmacy, 1-3 Clinicilor Street, 400006, Cluj- \\ Napoca, Romania \\ ${ }^{2}$ Department of Radiobiology and Tumour Biology, "Ion Chiricuță” Oncology Institute, 34-36 Republicii Street, 400015, \\ Cluj-Napoca, Romania \\ ${ }^{3}$ Department of Morphopathology, "Iuliu Hațieganu” University of Medicine and Pharmacy, 3-5 Clinicilor Street, 400006 \\ Cluj-Napoca, Romania \\ ${ }^{4}$ University of Agricultural Sciences and Veterinary Medicine, Department of Pathology, Cluj-Napoca, Romania \\ ${ }^{5}$ Ross University School of Veterinary Medicine, Department of Biomedical Sciences, Basseterre, St. Kitts, West Indies \\ ${ }^{6}$ Faculty of Chemistry and Chemical Engineering "Babeş-Bolyai” University, 11 Arany Janos Street, 400028, Cluj-Napoca, \\ Romania \\ ${ }^{7}$ Department of Preclinical Disciplines, Faculty of Medicine and Pharmacy, University of Oradea, 10 Piața 1 Decembrie \\ Street, 410073 Oradea, Romania
}

*corresponding author: rdmitrea@yahoo.co.uk

Manuscript received: May 2020

\begin{abstract}
Ischemia is a major cause of cardiovascular diseases, with an increased rate of morbidity and mortality, pathogenetically characterized by redox imbalance, inflammation and tissue damage. The aim of this study was to investigate the effects of grape seeds (Vitis vinifera L.) and elderberry fruit (Sambucus nigra L.) extracts on the gastrocnemius muscle lesions induced by the experimental femoral ischemia. The total polyphenolic content and the antioxidant activity of the two extracts were also evaluated. The effects of ischemia-reperfusion damage were investigated by quantification of oxidative stress, inflammation, matrix metalloproteinases-2 activity and histopathological analysis of the gastrocnemius muscle. Both extracts showed beneficial antioxidant effects, decreasing the lipid peroxidation in muscle homogenates. The administration of Vitis vinifera L. extract diminished the metalloproteinase-2 activity while the treatment with Sambucus nigra L. extract exerted potent antiinflammatory effects.
\end{abstract}

\section{Rezumat}

Ischemia este o cauză majoră a bolilor cardiovasculare, cu o rată crescută a morbidității și mortalității, caracterizată patogenetic prin dezechilibru redox, inflamație și leziuni tisulare. Scopul studiului a fost urmărirea efectelor administrării unui extract din sâmburi de struguri (Vitis vinifera L.) și ale unui extract din fructe de soc (Sambucus nigra L.) asupra leziunilor mușchiului gastrocnemian, induse de ischemia femurală experimentală. Conţinutul total de polifenoli şi activitatea antioxidantă a extractelor a fost de asemenea evaluată. Efectele nefavorabile ale ischemiei-reperfuziei au fost investigate prin cuantificarea stresului oxidativ, inflamației, activității metaloproteinazelor matriciale-2 și analiza histopatologică a mușchiului gastrocnemian. Ambele extracte au prezentat efecte benefice, diminuând peroxidarea lipidică în omogenatul muscular. Extractul de Vitis vinifera L. a scăzut activitatea metaloproteinazei-2, în timp ce tratamentul cu Sambucus nigra L. a exercitat efecte antiinflamatorii importante.

Keywords: ischemia-reperfusion, oxidative stress, inflammation, Sambucus nigra L., Vitis vinifera L. extracts

\section{Introduction}

Diseases caused by ischemia (myocardial infarction, stroke, peripheral vascular diseases) are among the most prevalent causes of morbidity and mortality globally [31]. The cell death and tissue lesions initially occur due to ischemic lesions, with the gravity and the duration of ischemia being the main factors that influence the degree of dysfunction. Consequently, the effectiveness of a therapy is related to the early initiation of revascularization and restoration of the blood flow in the damaged tissues. However, the vascular reperfusion exacerbates the inflammatory status in the affected organ, resulting in the so-called "reperfusion injury" [5].

The ischemia-reperfusion is a pathological event associated with imbalance between oxidants and antioxidants [33]; the oxidants synthesis surpasses the detoxifying capacity of the enzymatic antioxidants, and therefore a cascade of reactions is initiated leading 
to tissue lesions [23]. Granger and Korthuis demonstrated that the leukocytes post-ischemic recruitment and the microvascular barrier alteration are initiated by the free radicals that result from the ischemia-reperfusion. In addition, reactive oxygen species (ROS) induce proinflammatory phenomena through the promotion of the chemotactic substances and the formation of adhesion molecules via nuclear transcription factor NF-kB activation and expression of pro-inflammatory genes [20].

Metalloproteinase-2 (MMP-2), a constitutive enzyme found in almost all cells with a role in the degradation of the denatured collagen (gelatine) and of the type IV collagen, is activated by oxidative stress [24, 40, 42, 52]. In fact, MMP-2 can be considered a signal protease that acts rapidly as a response to the redox imbalance, especially as a response to $\mathrm{ONOO}^{-}$generated during post-ischemic reperfusion [8]. The MMP-2 activation inactivates the tissue inhibitors of metalloproteinases (TIMP) [18] and interferes with the regulation of new blood vessels development through the release of cytokines and growth factors [26]. During the last years, a special attention was given to the vegetal antioxidants, owing to their beneficial effects as antioxidant, anti-inflammatory and anti-apoptotic agents in different diseases. The grapes history starts from ancient Greek and Roman civilizations when they were venerated for their usage in wine production. Polyphenols are the most important phytochemicals from grapes with proven beneficial effects: antioxidant [29], cardioprotective, anticancer, anti-inflammatory, anti-aging and antibacterial [47]. Sambucus nigra L. (European elderberry), of the Adoxaceae family, contains flavonoids, glycosides, phenolic acids, free fatty acids, carotenoids, vitamins and minerals. The antioxidant activity of elderberry and its derivatives was confirmed through in vitro and in vivo studies [12] that proved the protective properties of the fruits, flowers and leaves [21].

The present study investigated the effects of grape seeds and elderberry fruits extracts on the muscle lesions induced by experimental femoral ischemia. The effect of ischemia-reperfusion damage and the impact of the fruit's polyphenols were evaluated in the gastrocnemius muscle by quantification of oxidative stress, inflammation, matrix metalloproteinases activity and histology. The total polyphenolic content and the antioxidant activity of the two extracts were also evaluated.

\section{Materials and Methods}

\section{Reagents}

Bradford reagent, Triton X-100, N-(1-naphthyl) ethylene diamine hydrochloride, sulphanilamide, glucose-6phosphate and glucose-phosphate dehydrogenase were purchased from Sigma-Aldrich Chemicals $\mathrm{GmbH}$ (Munich, Germany). 2,2'-azinobis-3-ethyl-benzthiazino- 6-sulphonic acid, Folin-Ciocâlteu phenol reagent, Trolox and 2-thiobarbituric acid were obtained from Merck KGaA (Darmstadt, Germany). Interleukin-6 ELISA kit was purchased from BioVendor, (Czech Republic). All reagents were of analytical grade. Preparation and characterization of fruits extracts The extract of Vitis vinifera L. (VV) Burgund Mare variety from Recaș (Romania) was obtained through dried grape seeds grinding $(1: 20 \mathrm{w} / \mathrm{v})$ that was mixed with water/ethanol solution, in ratio 50/50 (v/v) [38]. The total polyphenolic content was measured through spectrophotometry using the Folin-Ciocâlteu method [45]. The antioxidant activity was evaluated by 2,2'azino-bis(3-ethylbenzothiazoline-6-sulfonic) acid (ABTS) and DPPH test with 2,2-diphenyl-1-picrylhydrazyl as previously described [14, 16]. Additionally, the composition of grape seeds extract was analysed by high performance liquid chromatography (HPLC) [16]. The elderberry fruits Sambucus nigra L. (SN) were collected in Cluj-Napoca, Romania and stored at $-18^{\circ} \mathrm{C}$ before the extraction procedure. The frozen fruits (75 grams) were crushed and mixed with $300 \mathrm{~mL}$ food grade acetone. The mixture was shaken for one hour at room temperature and filtered. The obtained concentrate extract was stored at $4{ }^{\circ} \mathrm{C}$. The free radical scavenging capacity was estimated using the ABTS free radical method, slightly modified [11]. The FolinCiocâlteu method developed by Singleton [45] slightly modified [28] was used to determine the total phenolic content of the fruit extract. A calibration curve of gallic acid was used to convert the absorbance readings in total phenolic content which was expressed as g GAE/L. Experimental design

The study was performed in the Experimental Research Laboratory of the Physiology Department, "Iuliu Haţieganu" University of Medicine and Pharmacy, Cluj-Napoca, Romania. Wistar adult male rats (150 $170 \mathrm{~g}$ ) were acquired from the University's Biobase. They were hosted in cages, in standard environmental conditions (temperature $21 \pm 1^{\circ} \mathrm{C}$ degrees; $50-60 \%$ relative humidity), with $12 \mathrm{~h}$ light/12 h dark cycle, with access to food and water ad libitum. The rats were kept in the Experimental Research Laboratory for oneweek acclimatization before the experiments. All the experiments were performed under the guidelines of the Directive 89/609/EEC and had the approval of the Ethical Committee of "Iuliu Haţieganu" University of Medicine and Pharmacy, Cluj-Napoca.

Sixty rats were randomly divided into 6 groups $(n=10)$, as follows: control groups, with sham femoral ischemia (sham - I, II, III groups) and groups with femoral ischemia (IV, V, VI groups). Group I (sham + veh): sham and vehicle (phosphate-buffered saline - PBS); Group II (sham + VV): sham and $50 \mathrm{mg} / \mathrm{kg}$ b.w. Vitis vinifera L. extract; Group III (sham + SN): sham and 15 mg/kg b.w. Sambucus nigra L. extract; Group IV (isch + veh): femoral ischemia and vehicle; Group V (isch + VV): femoral ischemia and $50 \mathrm{mg} / \mathrm{kg} \mathrm{b.w}$. Vitis 
FARMACIA, 2021, Vol. 69, 1

vinifera $\mathrm{L}$. extract and Group VI (isch $+\mathrm{SN}$ ): ischemia and $15 \mathrm{mg} / \mathrm{kg}$ b.w. Sambucus nigra L. extract. Prior to the surgery, the rats received for 14 days, by oral gavage, the vehicle, VV or SN extracts. On day 14, under general anaesthesia with ketamine $10 \%$ and xylazine $2 \% 2: 1(0.1 \mathrm{~mL} / 100 \mathrm{~g})$ the surgical intervention was performed. Thus, groups I, II and III underwent a false (or sham) ischemia procedure while groups IV, $\mathrm{V}$ and VI were subjected to femoral ischemia by ligature realized at the emerging of deep femoral artery from the common iliac artery. Each group of rats was divided into other two subgroups: half of the animals received the extract by oral gavage another 7 days, and the other half, another 14 days after the surgery (Figure 1). On day 21, respectively 28, under general anaesthesia, gastrocnemius muscle samples were taken for biochemical and histopathological analysis.

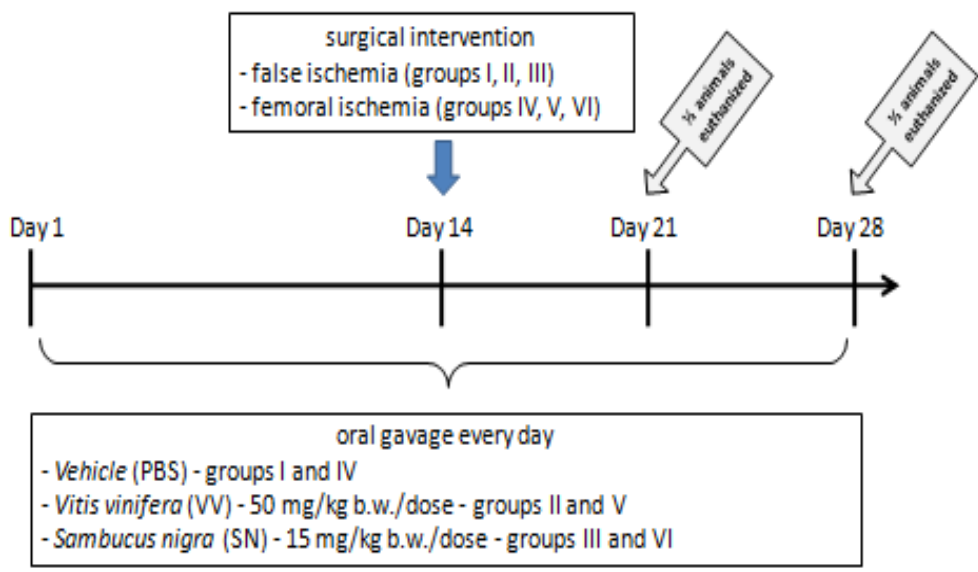

Figure 1.

Experimental design

\section{Biochemical assays}

Gastrocnemius muscle samples were collected, from each animal, for oxidative stress and inflammation evaluation and for histopathological investigations. For biochemical evaluation the muscle homogenates prepared with Polytron homogenizer were used. Homogenization was performed in buffer consisting of $50 \mathrm{mM}$ Tris, with $\mathrm{pH}=7.4$ and $10 \mathrm{mM}$ EDTA ( $1 / 4=$ weight/volume). The sample was cold centrifuged for 5 minutes at $5000 \mathrm{rpm}$. The levels of malondialdehyde (MDA) [10] and nitric oxide (NO) [46] and also the catalase activity (CAT) [37] were assessed.

To determine MDA, muscle homogenate (conc. $50 \mu \mathrm{L}$ ) was boiled for 1 hour on a water bath with a solution of thiobarbituric acid $(10 \mathrm{mM})$ in $\mathrm{K}_{2} \mathrm{HPO}_{4}(75 \mathrm{mM})$ with $\mathrm{pH}=3(1 \mathrm{~mL})$. The reaction product was suddenly cooled and extracted into n-butanol. It was separated by centrifugation, and the concentration was determined in the organic phase. Using a spectrophotometer, the emission intensity was quantified at $534 \mathrm{~nm}$ in the synchronous fluorescence system, at a wavelength difference $(\Delta \lambda)$ between excitation and emission of $14 \mathrm{~nm}$. A curve with known concentrations of MDA, processed in the same way, was used as a standard. Values were expressed in $\mathrm{nmol} / \mathrm{mg}$ protein.

NO was measured by the Griess method for nitrite and nitrate, through a two-step procedure. In the first step, the nitrate in the sample was reduced to nitrite using a conversion buffer containing glucose-6-phosphate (2.5 mM), glucose-phosphate dehydrogenase (final concentration $400 \mathrm{U} / \mathrm{I}$ ) and NADPH-dependent nitrate reductase (200 U/I) in sodium phosphate buffer (14 $\mathrm{mM})$, at $\mathrm{pH}=7.4$ and a solution of NADPH $(0.02$ $\mathrm{mmol})$. Incubation was followed by precipitation of the proteins with $\mathrm{ZnSO}_{4}(3.5 \mathrm{M})$. After centrifugation, the supernatant was treated with Griess reagent (equal concentrations of $0.1 \mathrm{~N}$-1-naphthyl ethylene diamine hydrochloride in $100 \mathrm{~mL}$ of water and $1 \mathrm{~g}$ of sulphanilamide in $100 \mathrm{~mL}$ of $5 \%$ orthophosphoric acid). The absorbance of the samples was interpreted at $540 \mathrm{~nm}$. The nitrite concentration was calculated compared to a standard nitrite curve. Values were expressed in $\mathrm{nmol} / \mathrm{mg}$ protein.

CAT was evaluated with a mixture of reagents consisting of hydrogen peroxide $(10 \mathrm{mM})$ and phosphate buffer $(50 \mathrm{mM})$ with $\mathrm{pH}=7.4$. Absorption was recorded at $240 \mathrm{~nm}$ for 3 minutes. The unit of enzymatic activity is the amount of enzyme that reduces the absorbance by $0.43 /$ minute at 25 degrees and is expressed in units/ $\mathrm{g}$ protein.

IL-6 in muscle homogenate was measured using Rat Interleukin-6 ELISA kit (BioVendor, Czech Republic) according to the manufacturer's instructions.

For evaluation of metalloproteinase activity, the zymography was used [19]. Samples were homogenized with Ultra Turrax in a medium with $2 \%$ glycerine and $2 \%$ SDS in $62.5 \mathrm{mM}$ Tris- $\mathrm{HCl}$ buffer. After centrifugation, the protein in the supernatant was determined by a modification of Lowry's method. Five $\mu \mathrm{g}$ protein samples were subjected to $10 \%$ polyacrylamide gel electrophoresis copolymerized with $1 \mathrm{~g} / \mathrm{mL}$ gelatine at $100 \mathrm{~V}$ for 2 hours. After electrophoresis, 
the gels were washed for one hour with $2.5 \%$ Triton $\mathrm{X}-100$ solution, then incubated for 18 hours at $37^{\circ} \mathrm{C}$ in $50 \mathrm{mM}$ Tris- $\mathrm{HCl}$ buffer at $\mathrm{pH}$ 7.4. Subsequently, the gels were stained with $1 \%$ Coomassie Brilliant Blue R-250 solution for 2 hours and then discoloured in $10 \%$ acetic acid solution. Proteolytic activity appears as clear white bands on a blue gel. The quantification of activities was performed using an automated image analyser VILBER-LOURMET based on the Bio $1 \mathrm{D}$ program. The proteolytic activity was confirmed with an enzymatic marker and reported as arbitrary units/ $\mu \mathrm{g}$ protein.

Histopathological investigation

Gastrocnemius muscles were dissected and fixed in $10 \%$ neutral buffered formalin, for 24 hours. Samples were cross-sectioned into slices with a thickness of about $5 \mathrm{~mm}$ and then embedded in paraffin. Histological serial sections of $5 \mu \mathrm{m}$ thickness were cut and stained with haematoxylin and eosin (H\&E). The samples were examined using a conventional light microscope (Olympus BX 43) equipped with an Olympus DP 26 digital camera and cellSens Standard image analysis software. For quantification of the number of nuclei per microscopic field, the H\&E stained muscle sections were used. The number of nuclei in structures compatible with capillaries from 6 different fields (magnification $\times 400$ ) was calculated, in accordance with a previously published technique [22].

\section{Data analysis}

The obtained data were statistically analysed using GraphPad Prism version 5.0 for Windows, GraphPad Software, (San Diego California USA), performing One-way ANOVA followed by the Tukey-test. The significance threshold was set at $\mathrm{p}<0.05$.

\section{Results and Discussion}

Evaluation of antioxidant activity of fruits extracts The antioxidant capacity of Vitis vinifera $\mathrm{L}$. was more important than that of the gallic acid, measured through ABTS (52.89 \pm 0.02 vs. $6.3 \pm 0.4 \mathrm{mM}$ Trolox) [16] and DPPH tests $(0.072 \pm 0.002$ vs. $0.083 \pm 0.004$ $\mathrm{mmol} / \mathrm{mmol} \mathrm{DPPH})$ [14]. Previous published data on HPLC analysis showed that VV extract is rich in procyanidin $\mathrm{B}$, catechin hydrate, epigallocatechin, epicatechin and gallic acid [36]. Sambucus nigra L. fruits contain high amounts of phenolic compounds, especially flavonoids and anthocyanin pigments which confer their dark colour. These bioactive compounds are responsible for their antioxidant activity [49]. The antioxidant capacity of the elderberry fruit extract assessed by the ABTS method was $16.42 \pm 0.58 \mathrm{mM}$ Trolox while the total phenolic content assessed by Folin-Ciocâlteu method was $10.42 \pm 0.4 \mathrm{~g} \mathrm{GAE} / \mathrm{L}$ fruit extract.

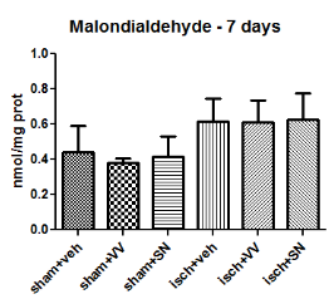

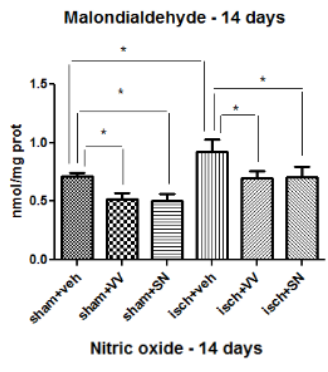

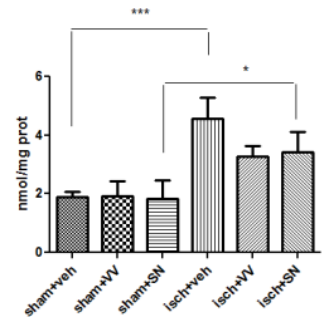

Catalase $\cdot 14$ days

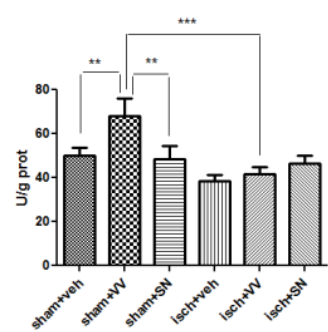

A

B

C

Figure 2.

Oxidative and nitrosative stress assessment in gastrocnemius muscle homogenates (A) Malondialdehyde levels, (B) Nitric oxide, (C) Catalase activity 
The evaluation of oxidative stress parameters $M D A$ increased at 7 days after surgery in groups with femoral ligature, compared to control groups, but without significant variations $(\mathrm{p}>0.05)$. At 14 days after surgery, the rats treated with Vitis vinifera L. (sham + $\mathrm{VV}$ ) and Sambucus nigra L. (sham $+\mathrm{SN}$ ) extracts showed significant decreases of MDA levels in comparison with animals treated with vehicle (sham + veh) $(\mathrm{p}<0.05)$. Similar changes were noted also in the ischemia group. No significant differences were recorded among the groups subjected to ischemia and treated with extracts (Figure 2).

$N O$ did not show significant variations in groups at 7 days after the surgical intervention. At 14 days, in the muscle homogenate of isch + veh group, NO increased significantly, compared to sham + veh group $(p<0.001)$. NO levels increased significantly in rats subjected to ischemia and treated with Sambucus nigra L. (isch + $\mathrm{SN})$, compared to sham rats treated with SN extract $($ sham $+\mathrm{SN})(\mathrm{p}<0.05)($ Figure 2$) . C A T$ activities diminished significantly at 7 days after surgery in the rats with ischemia treated cu vehicle $(\mathrm{p}<0.05)$ compared to sham + veh, and in ischemia treated with Vitis vinifera L. extract compared to sham group treated with the same extract $(\mathrm{p}<0.05)$. At 14 days, CAT activities improved in the sham group treated with Vitis vinifera L. (sham $+\mathrm{VV})$, compared to other two sham groups (sham + veh and sham $+\mathrm{SN})(\mathrm{p}<0.01)$ and compared to the isch $+\mathrm{VV}$ group $(\mathrm{p}<0.001)$ (Figure 2).

The evaluation of inflammatory markers

At 7 days after surgery, IL-6 levels did not show significant variations among the groups. At 14 days after femoral ligature, in the rats with ischemia treated with SN extract, IL-6 levels decreased significantly, compared to those treated with vehicle $(p<0.05)$. In the sham group treated with Sambucus nigra L. extract, IL-6 levels were lower than those recorded in the other control groups (sham + veh, respectively sham + VV) $(\mathrm{p}<0.05)$ (Figure 3).
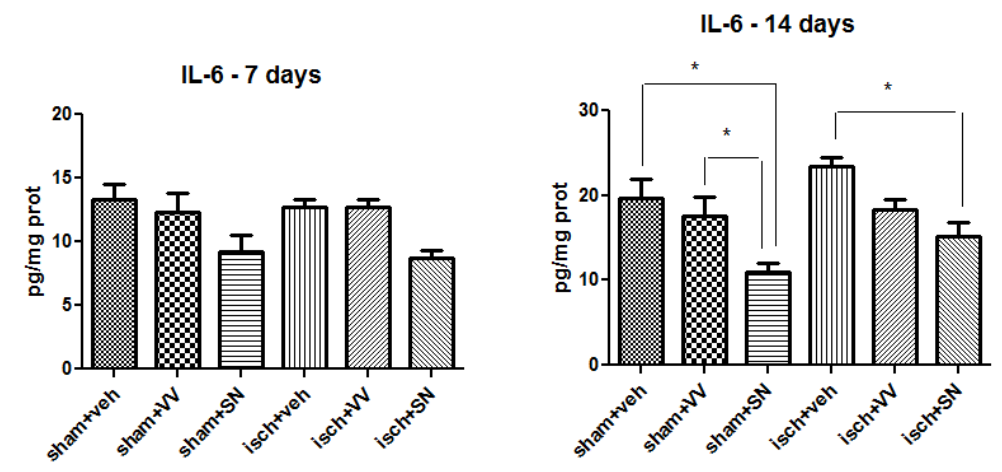

Figure 3.

IL-6 assessment in gastrocnemius muscle homogenates

The metalloproteinase MMP-2 activity

Analysis of zymographic images revealed the presence of immature form or proenzyme MMP-2 in all studied groups. At 7 days after surgery, in ischemia group treated with Vitis vinifera L. extract, the activity of MMP-2 decreased

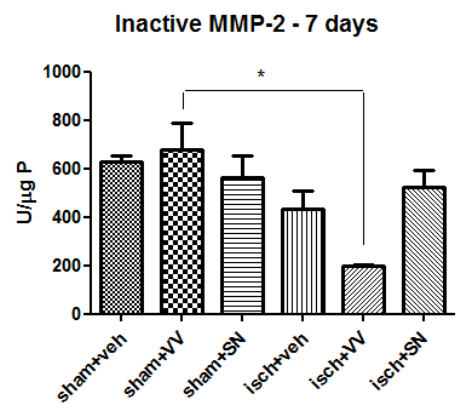

significantly compared to the sham group that received the same extract (sham $+\mathrm{VV})(\mathrm{p}<0.05)$. At 14 days after surgery, the results did not show any significant modifications among the groups (Figure

4).

Figure 4.

MMP-2 activity in gastrocnemius muscle homogenates

Histopathological analysis

No signs of inflammation, degeneration, necrosis or loss of myofibers were observed in either of the groups at both experimental times. No morphological differences were seen between these groups. The results of the quantification of the number of nuclei/fields in 
structures compatible with capillaries are shown in Figure 5. There is an insignificant variation between
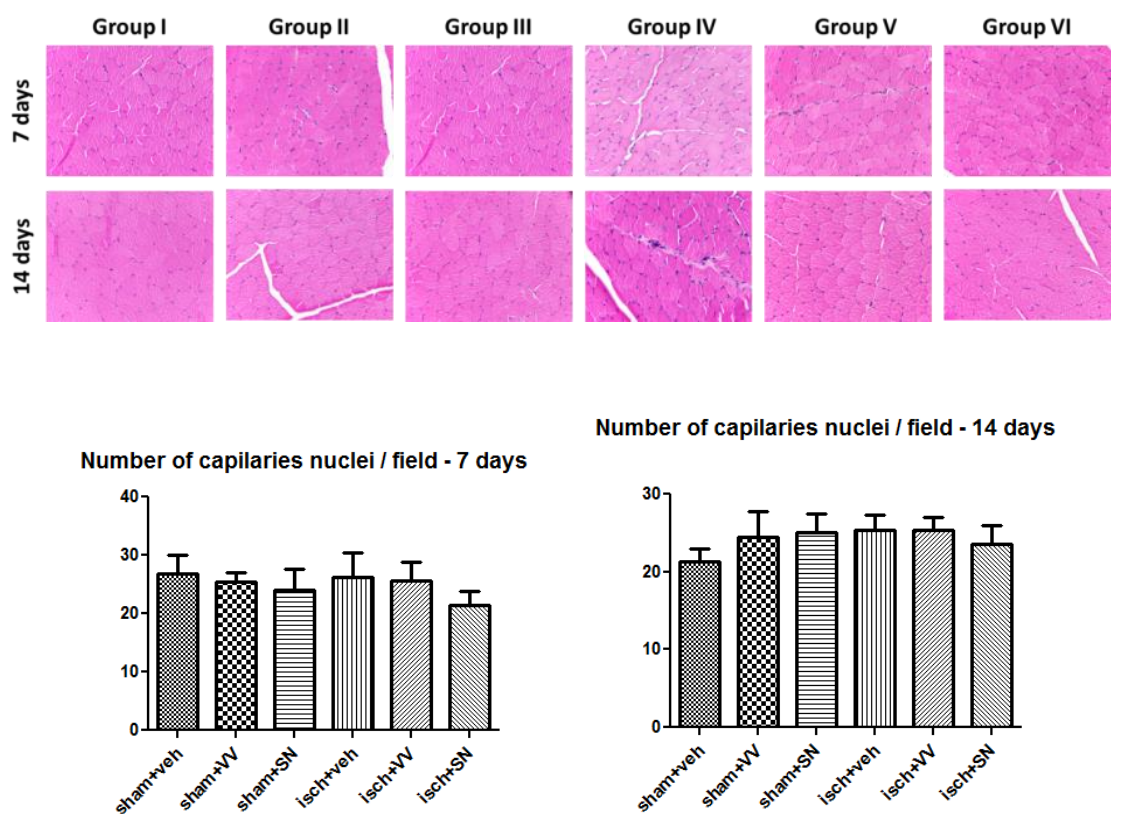

Histopathological images (A) and the quantification of the number of nuclei/fields (B) in gastrocnemius muscle sections, at the two experimental times

Our study, performed on an experimental femoral ischemia-reperfusion model in rats, investigated the protective effects of two natural extracts (Vitis vinifera L. and Sambucus nigra L.), well-known for their content of antioxidants, the high degree of tolerability and for their affordability. We chose the doses of the preparations based on literature data and personal experience. The effects were quantified by measuring the oxidative stress and inflammation parameters and by the investigation of matrix metalloproteinases activity. The morphological changes in the muscle were also assessed, taken at 7 and 14 days after the surgical procedure. It is known that ROS (reactive oxygen species) contribute to the development of skeletal muscle lesions, associated to the ischemia-reperfusion events [25]. Thus, Büttemeyer et al. measured in rats the concentration of oxygen radicals $\left(\mathrm{O}_{2}^{-}\right)$in the gastrocnemius muscle during reperfusion, after 60 and 120 minutes of femoral ischemia and demonstrated that epigallocatechin gallatte decreased the $\mathrm{O}_{2}{ }^{-}$tissue level, compared to the animals without treatment [4]. Our results confirmed the in vivo antioxidant effects for both extracts (Vitis vinifera L. and Sambucus nigra L.), with significant decreases of MDA levels in the gastrocnemius muscle in all groups treated with antioxidants, compared to vehicle, but only at 14 days after surgery. The literature data regarding the role of polyphenols from elderberry and grape seeds on femoral ischemia are scarce. However, Simão et al. demonstrated that the administration of resveratrol from grapes, 7 days before the transitory ischemia in rats, significantly diminished the neuronal death, ROS production, lipid peroxidation and NO levels [44]. Other researchers noticed the favourable effects of resveratrol in rats with renal ischemia-reperfusion [7], intestinal ischemia [32] or myocardial ischemia [13]. In addition, previous studies confirmed the favourable effects of whole-grape suspension in ischemia-reperfusion in the urinary bladder of rabbits [17], the beneficial effects of grape polyphenol extract in neuronal lesions on cerebral ischemia in gerbils $[50,51]$.

Some researchers have studied the effects of other compounds from grape seeds, such as procyanidines or gallic acid, also present in our extract, in different pathological conditions associated with ischemiareperfusion. They observed the antioxidant action of gallic acid in hepatic [3], or renal [1] ischemia. Similarly, proanthocyanidins had cardioprotective effects against reperfusion-induced injury in isolated rat hearts [35]. These data brought solid arguments for the beneficial effects of Vitis vinifera extract in ischemia-reperfusion lesions. In addition, the HPLC profile of Sambucus nigra fruits mainly concerning their phenolic acid and flavonoid derivatives revealed the presence of five anthocyanins cyanidin derivatives: cyanidin-3sambubioside-5-glucoside, cyanidin-3,5-diglucoside, cyanidin-3-sambubioside, cyanidin-3-glucoside and cyanidin-3-rutinoside, the most abundant being cyanidin-3-sambubioside. The neuroprotective effect of cyanidin-3-O-glucoside anthocyanin was demonstrated by Min et al. in mice with focal cerebral ischemia, the tested compound reduced the oxidative stress and the 
FARMACIA, 2021, Vol. 69, 1

infarct size with $25 \%$ and improved the neurological functional outcome [27]. Elderberry administered for 2 months prior to a $30 \mathrm{~min}$ global cerebral ischemia and reperfusion for 3 days has improved the sensorimotor impairment, reduced the neuronal death and diminished the expression of p47phox, a subunit of NADPH oxidase, and phospho-ERK1/2, enzymes involved in oxidative stress and inflammation in brain [9]. The black elderberry fruits also contain high amounts of quercetin derivatives which were also identified by HPLC, among these quercetin-3-rutinoside being the main one [48]. The chromatographic fingerprint of elderberry extracts also showed the presence of other flavonols such as rutin, myricetin and kaempferol. In our research, at 14 days after surgery, in ischemia groups treated with vehicle or Sambucus nigra L. extract, the NO levels increased significantly compared to the sham groups, but without significant differences among ischemia groups. The effects of polyphenols on the NO levels were explained extensively in a study performed by Rodrigo and Bosco, on experimental renal ischemia [41]. They tested the polyphenols from red wine, demonstrating that the reno-protective effects are produced mainly by the release of $\mathrm{NO}$, as a result of the increase of the endothelial nitric oxide synthase (eNOS) expression. The NO production under eNOS activation depends on cofactor tetrahydrobiopterin (BH4). At high levels of ROS, BH4 is oxidized; eNOS is decoupled, leading to increased concentration of superoxide anion and to decrease NO levels. The increase of antioxidants' bioavailability increased BH4 levels, reduced superoxide anion production and amplified the NO production. The literature data related to the NO role in ischemia-reperfusion lesion are contradictory and depend on the used experimental model, localization and area of ischemia, and the dynamic of parameters. Shen et al. demonstrated that pre-treatment with resveratrol in rats with myocardial ischemia followed by reperfusion increased NO and reduced MDA in myocardium [43]. Similar results were also obtained in our study: polyphenols administration increased NO levels in ischemia groups, compared to sham groups, but at lower levels than those of the ischemia-vehicle group. The antioxidant protection was quantified through catalase activity. At 14 days after surgery, CAT activity was improved in the sham group treated with Vitis vinifera L. extract, compared to other two sham groups, suggesting the protective antioxidant role of this natural compound. Similar results were noticed by Nakagawa et al. on rats with renal ischemia-reperfusion: CAT and glutathione peroxidase activities increased after proanthocyanidinrich extract administration [30].

Prabhakar studied the cerebroprotective effects of resveratrol in diabetic rats with ischemia-reperfusion and noticed the dose-dependent effects. Low levels of MDA and inflammatory markers including TNF- $\alpha$, IL-6 and myeloperoxidase activity and significant improvement of antioxidant and anti-inflammatory markers (CAT, SOD, IL-10) were found after $20 \mathrm{mg} / \mathrm{kg}$ b.w. of resveratrol administration [39]. In our study, in the muscle homogenates, IL-6 levels decreased at 14 days after ischemia in animals that received Sambucus nigra L., suggesting the late protection produced by this extract administration. MMP-2, matrix metalloproteinase that belongs to the zinc-dependent endopeptidase family, is involved in various physiological and pathophysiological mechanisms. In general, MMP2 may regulate new vessels formation through the cytokines and growth factor release [26]. In our study, at 7 days after surgery, the animals with ischemia treated with VV extract showed lower MMP-2 activities than the sham group treated with the same natural compound, supporting the beneficial effect of polyphenols in MMP-2 activity regulation. Similar results on MMP-2 were obtained with resveratrol in studies performed on experimental cerebral ischemia-reperfusion $[6,15,34]$. The density of vessels in the gastrocnemius muscle was evaluated by counting the endothelial nuclei per 6 microscopic fields (x400). The morphological results did not reveal significant increases of nuclei in the areas with ischemia-reperfusion, protected by extracts administration, probably due to sub-microscopic, molecular changes induced by polyphenols in this model of ischemia. Another explanation is offered by Baron-Menguy et al. who demonstrated the paradoxical effects of red wine polyphenols on angiogenesis in experimental ischemia: they protect against noxious effect induced by ischemia at the cerebral and heart level through pro-angiogenic properties, stimulating the growth of new blood vessels in the ischemic area, but, on the other hand, the polyphenols inhibit the angiogenesis [2]. In fact, these paradoxical effects depended on the polyphenols concentration. The inhibitory effects were observed at high doses $(20 \mathrm{mg} / \mathrm{kg} \mathrm{b.w.)}$ of polyphenols, while the low doses $(0.2 \mathrm{mg} / \mathrm{kg} \mathrm{b} . \mathrm{w}$.) had stimulatory effects on angiogenesis. These contradictory data emphasize the complexity of mechanisms that occur in ischemia-reperfusion and bring arguments for dynamic studies to identify the subtle alterations induced by vascular damage. The obtained results are promising for the development of complementary therapies with natural extracts in ischemic related conditions. The literature data sustain this idea. Thus, Chuang et al. found that Sambucus nigra L. protected against the functional motor deficiencies induced by the cerebral ischemia and attenuated the neuropathological consequences, including the neuronal death, activating microglia [9].

\section{Conclusions}

The ischemia-reperfusion mechanism induced an imbalance of the redox status in muscle, increasing the lipid peroxidation and NO synthesis. The administration of natural extracts had beneficial effects: it diminished 
the oxidative stress, increased the antioxidant protection and reduced the MMP-2 activity. Sambucus nigra L. extract had more important anti-inflammatory effects than Vitis vinifera L. Our findings indicated that the administration of one of these extracts may improve the tissue redox status and inflammation in conditions related to ischemia-reperfusion and highlighted the complementary protective role of polyphenols extracts in ischemia prevention and treatment.

\section{Conflict of interest}

The authors declare no conflict of interest.

\section{References}

1. Ahmadvand H, Yalameha B, Adibhesami G, Nasri M, Naderi N, Babaeenezhad E, Nouryazdan N, The Protective Role of Gallic Acid Pretreatment On Renal Ischemia-reperfusion Injury in Rats. Rep Biochem Mol Biol., 2019; 8(1): 42-48.

2. Baron-Menguy C, Bocquet A, Guihot AL, Chappard D, Amiot MJ, Andriantsitohaina R, Loufrani L, Henrion D, Effects of red wine polyphenols on postischemic neovascularization model in rats: low doses are proangiogenic, high doses anti-angiogenic. The FASEB Journal, 2007; 21(13): 3511-3521.

3. Bayramoglu G, Kurt H, Bayramoglu A, Gunes HV, Degirmenci I, Colak S, Preventive role of gallic acid on hepatic ischemia and reperfusion injury in rats. Cytotechnology, 2015; 67(5): 845-849.

4. Büttemeyer R, Philipp AW, Schlenzka L, Mall JW, Beissenhirtz M, Lisdat F, Epigallocatechin gallate can significantly decrease free oxygen radicals in the reperfusion injury in vivo. Transplant Proc., 2003; 35(8): 3116-3120.

5. Carden DL, Granger DN, Pathophysiology of ischaemiareperfusion injury. J Pathol., 2000; 190(3): 255-266.

6. Cavdar Z, Egrilmez MY, Altun ZS, Arslan N, Yener $\mathrm{N}$, Sayin O, Genc S, Genc K, Islekel H, Oktay G, Resveratrol reduces matrix metalloproteinase- 2 activity induced by oxygen-glucose deprivation and reoxygenation in human cerebral microvascular endothelial cells. Int J Vitam Nutr Res., 2012; 82(4): 267-274.

7. Chander V, Chopra K, Role of nitric oxide in resveratrol-induced renal protective effects of ischemic preconditioning. J Vasc Surg., 2005; 42(6): 1198-1205.

8. Chow AK, Cena J, Schulz R, Acute actions and novel targets of matrix metalloproteinases in the heart and vasculature. Br J Pharmacol., 2007; 152(2): 189-205.

9. Chuang DY, Cui J, Simonyi A, Engel VA, Chen S, Fritsche KL, Thomas AL, Applequist WL, Folk WR, Lubahn DB Sun AY, Sun GY, Gu Z, Dietary Sutherlandia and Elderberry Mitigate Cerebral IschemiaInduced Neuronal Damage and Attenuate p47phox and Phospho-ERK1/2 Expression in Microglial Cells. ASN Neuro., 2014; 6(6): 175909141455494: 1-14.

10. Conti M, Morand PC, Levillain P, Lemonnier A, Improved fluorometric determination of malonaldehyde. Clin Chem., 1991; 37(7): 1273-1275.

11. David L, Danciu V, Moldovan B, Filip A, Effects of in vitro gastrointestinal digestion on the antioxidant capacity and anthocyanin content of Cornelian cherry fruit extract. Antioxidants, 2019; 8(5):114: 1-9.
12. Dawidowicz AL, Wianowska D, Baraniak B, The antioxidant properties of alcoholic extracts from Sambucus nigra L. (antioxidant properties of extracts). LWT - Food Science and Technology, 2006; 39(3): 308-315.

13. Dernek S, Ikizler M, Erkasap N, Ergun B, Koken T, Yilmaz K, Sevin B, Kaygisiz Z, Kural T, Cardioprotection with resveratrol pretreatment: improved beneficial effects over standard treatment in rat hearts after global ischemia. Scand Cardiovasc J., 2004; 38(4): 245-254.

14. Dicu T, Postescu ID, Tatomir C, Tamas M, Dinu A, Cosma C, A novel method to calculate the antioxidant parameters of the redox reaction between polyphenolic compounds and the stable DPPH radical. Ital $J$ Food Sci., 2010; 22(3): 333-339.

15. Dong W, Li N, Gao D, Zhen H, Zhang X, Li F, Resveratrol attenuates ischemic brain damage in the delayed phase after stroke and induces messenger RNA and protein express for angiogenic factors. $J$ Vasc Surg., 2008; 48(3): 709-714.

16. Filip A, Daicoviciu D, Clichici S, Mocan T, Muresan A, Postescu ID, Photoprotective effects of two natural products on UVB-induced oxidative stress and apoptosis in SKH-1 mice skin. J Med Food, 2011; 14(7-8): 761-766.

17. Francis JA, Leggett RE, Schuler C, Levin RM, Effect of hydrogen peroxide on contractility and citrate synthase activity of the rabbit urinary bladder in the presence and absence of resveratrol and a whole-grape suspension. Mol Cell Biochem., 2014; 391(1-2): 233-239.

18. Frears ER, Zhang Z, Blake DR, O'Connell JP, Winyard $\mathrm{PG}$, Inactivation of tissue inhibitor of metalloproteinase1 by peroxynitrite. FEBS Lett., 1996; 381(1-2): 21-24.

19. Granelli-Piperno A, Reich E, A study of proteases and protease-inhibitor complexes in biological fluids. J Exp Med., 1978; 148(1): 223-234.

20. Granger DN, Korthuis RJ, Physiologic mechanisms of postischemic tissue injury. Annu Rev Physiol., 1995; 57(1): 311-332.

21. Jeandet P, Bessis R, Maume B, Meunier P, Peyron D, Trollat P, Effect of Enological Practices on the Resveratrol Isomer Content of Wine. J Agric Food Chem., 1995; 43(2): 316-319.

22. Kakinuma Y, Furihata M, Akiyama T, Arikawa M, Handa T, Katare RG, Sato T, Donepezil, an acetylcholinesterase inhibitor against Alzheimer's dementia, promotes angiogenesis in an ischemic hindlimb model. $J$ Mol Cell Cardiol., 2010; 48(4): 680-693.

23. Kalogeris T, Baines CP, Krenz M, Korthuis RJ, Ischemia/Reperfusion. Compr Physiol., 2016; 7(1): 113-170.

24. Kameda K, Matsunaga T, Abe N, Hanada H, Ishizaka H, Ono H, Saitoh M, Fukui K, Fukuda I, Osanai T, Okumura K, Correlation of oxidative stress with activity of matrix metalloproteinase in patients with coronary artery disease. Possible role for left ventricular remodeling. Eur Heart J., 2003; 24(24): 2180-2185.

25. Lindsey M, Wedin K, Brown M, Keller C, Evans A, Smolen J, Burns AR, Rossen RD, Michael L, Entman M, Matrix-dependent mechanism of neutrophil-mediated release and activation of matrix metalloproteinase 9 in myocardial ischemia/reperfusion. Circulation, 2001; 103(17): 2181-2187. 
26. Löffek S, Schilling O, Franzke C-W, Series: Matrix metalloproteinases in lung health and disease: Biological role of matrix metalloproteinases: a critical balance. Eur Respir J., 2011; 38(1): 191-208.

27. Min J, Yu SW, Baek SH, Nair KM, Bae ON, Bhatt A, Kassab M, Nair MG, Majid A, Neuroprotective effect of cyanidin-3-O-glucoside anthocyanin in mice with focal cerebral ischemia. Neurosci Lett., 2011; 500(3): 157-161.

28. Moldovan B, Popa A, David L, Effects of storage temperature on the total phenolic content of Cornelian cherry (Cornus mas L.) fruits extracts. J Appl Bot Food Qual., 2016; 89: 208-211.

29. Moldovan ML, Bogdan C, Iurian S, Roman C, Oniga I, Benedec D, Phenolic content and antioxidant capacity of pomace and canes extracts of some Vitis Vinifera varieties cultivated in Romania. Farmacia, 2020; 68(1): $15-21$

30. Nakagawa T, Yokozawa $\mathrm{T}$, Satoh A, Kim HY, Attenuation of renal ischemia-reperfusion injury by proanthocyanidin-rich extract from grape seeds. $J$ Nutr Sci Vitaminol., 2005; 51(4): 283-286.

31. Ndrepepa G, Atherosclerosis \& ischaemic heart disease: Here to stay or gone tomorrow. Indian J Med Res., 2017; 146(3): 293-297.

32. Ozkan OV, Yuzbasioglu MF, Ciralik H, Kurutas EB, Yonden Z, Aydin M, Bulbuloglu E, Semerci E, Goksu M, Atli Y, Bakan V, Duran N, Resveratrol, a natural antioxidant, attenuates intestinal ischemia/reperfusion injury in rats. Tohoku J Exp Med., 2009; 218(3): 251-258.

33. Ozturk H, Cetinkaya A, Erdogan Duzcu S, Yis OM, Ozturk H, Carvacrol reduces the severity of intestinal mucosal damage caused by intestinal ischemia-reperfusion in rats. Farmacia, 2019; 67(5): 892-898.

34. Pandey AK, Bhattacharya P, Shukla SC, Paul S, Patnaik $\mathrm{R}$, Resveratrol inhibits matrix metalloproteinases to attenuate neuronal damage in cerebral ischemia: a molecular docking study exploring possible neuroprotection. Neural Regen Res., 2015; 10(4): 568-575. Erratum in: Neural Regen Res., 2020; 15(9): 1708.

35. Pataki T, Bak I, Kovacs P, Bagchi D, Das DK, Tosaki A, Grape seed proanthocyanidins improved cardiac recovery during reperfusion after ischemia in isolated rat hearts. Am J Clin Nutr., 2002; 75(5): 894-899.

36. Perde-Schrepler M, Chereches G, Brie I, Tatomir C, Postescu ID, Soran L, Filip A, Grape seed extract as photochemopreventive agent against UVB- induced skin cancer. J Photochem Photobiol B: Biology, 2013, 118: 16-21.

37. Pippenger CE, Browne RW, Armstrong D, Regulatory antioxidant enzymes. In: Armstrong D (Ed.), Free Radical and Antioxidant Protocols. Methods in Molecular Biology, Humana Press Inc., Totowa NJ, 1998; 108: 299-313

38. Postescu ID, Tatomir C, Cherecheş G, Brie I, Damian G, Petrișor D, HosuA-M, Miclăuș V, Pop A, Spectroscopic characterization of some grape extracts with potential role in tumor growth inhibition. J Optoelectron $A d v$ Mater., 2007; 9(3): 564-567.

39. Prabhakar O, Cerebroprotective effect of resveratrol through antioxidant and anti-inflammatory effects in diabetic rats. Naunyn Schmiedebergs Arch Pharmacol., 2013; 386(8): 705-710.

40. Pustovrh MC, Jawerbaum A, Capobianco E, White V, Martínez N, López-Costa JJ, González E, Oxidative stress promotes the increase of matrixmetalloproteinases2 and -9 activities in the feto-placental unit of diabetic rats. Free Radical Research, 2005; 39(12): 1285-1293.

41. Rodrigo R, Bosco C, Oxidative stress and protective effects of polyphenols: comparative studies in human and rodent kidney. A review. Comp Biochem Physiol C Toxicol Pharmacol., 2006; 142(3-4): 317-327.

42. Sawicki G, Intracellular regulation of matrix metalloproteinase-2 activity: new strategies in treatment and protection of heart subjected to oxidative stress. Scientifica, 2013; 2013: 130451: 1-13.

43. Shen M, Jia GL, Wang YM, Ma H, Cardioprotective effect of resvaratrolpretreatment on myocardial ischemiareperfusion induced injury in rats. Vascul Pharmacol., 2006; 45(2): 122-126.

44. Simão F, Matté A, Matté C, Soares FM, Wyse AT, Netto CA, Salbego CG, Resveratrol prevents oxidative stress and inhibition of $\mathrm{Na}(+) \mathrm{K}(+)$-ATPase activity induced by transient global cerebral ischemia in rats. J Nutr Biochem., 2011; 22(10): 921-928.

45. Singleton VL, Orthofer R, Lamuela-Raventós RM, Analysis of total phenols and other oxidation substrates and antioxidants by means of Folin-Ciocalteu reagent. Methods in Enzymology, 1999; 299: 152-178.

46. Titheradge M, Nitric Oxide Protocols. In Methods in Molecular Biology, Humana Press, 1998; 100: 111-127.

47. Tsang C, Higgins S, Duthie GG, Duthie SJ, Howie M, Mullen W, Lean MEJ, Crozier A, The influence of moderate red wine consumption on antioxidant status and indices of oxidative stress associated with CHD in healthy volunteers. Br J Nutr., 2005; 93(2): 233-240.

48. Veberic R, Jakopic J, Stampar F, Schmitzer V, European elderberry (Sambucus nigra L.) rich in sugars, organic acids, anthocyanins and selected polyphenols. Food Chem., 2009; 114: 511-515.

49. Viapiana A, Wesolowski M, The phenolic contents and antioxidant activities of infusions of Sambucus nigra L. Plant Foods Hum Nutr., 2017; 72: 82-87.

50. Wang Q, Simonyi A, Li W, Sisk BA, Miller RL, Macdonald RS, Lubahn DE, Sun GY, Sun AY, Dietary grape supplement ameliorates cerebral ischemia-induced neuronal death in gerbils. Mol Nutr Food Res., 2005; 49(5): 443-451.

51. Wang Q, Sun AY, Simonyi A, Miller DK, Smith RE, Luchtefeld RG, Korthuis RJ, Sun GY, Oral administration of grape polyphenol extract ameliorates cerebral ischemia/reperfusion-induced neuronal damage and behavioral deficits in gerbils: comparison of preand post-ischemic administration. J Nutr Biochem., 2009; 20(5): 369-377.

52. Yang Y, Candelario-Jalil E, Thompson JF, Cuadrado E, Estrada EY, Rosell A, Montaner J, Rosenberg GA, Increased intranuclear matrix metalloproteinase activity in neurons interferes with oxidative DNA repair in focal cerebral ischemia. J Neurochem., 2010; 112(1): 134-149. 